Joachim Boldt

Thorsten Brenner

Andreas Lehmann

Johannes Lang

Bernhard Kumle

Christiane Werling

\section{Retraction Note: Influence of two different volume replacement regimens on renal function in elderly patients undergoing cardiac surgery: comparison of a new starch preparation with gelatin}

Published online: 21 May 2011

(C) Copyright jointly held by Springer and ESICM 2011

The online version of the original article can be found under doi:10.1007/s00134-003-1702-6.

J. Boldt ( $)$ - T. Brenner · A. Lehmann · J. Lang · B. Kumle Department of Anesthesiology and Intensive Care Medicine, Klinikum der Stadt Ludwigshafen,

Bremserstrasse 79, 67063 Ludwigshafen, Germany

e-mail: BoldtJ@gmx.net

Fax: +49-621-5033024

C. Werling

Clinic of Cardiac Surgery, Klinikum der Stadt Ludwigshafen, Ludwigshafen, Germany

\section{Retraction Note: Intensive Care Med (2003)} 29:763-769

DOI 10.1007/s00134-003-1702-6

This article has been retracted as the IRB approval for the research was misrepresented. The investigating committee at Klinikum Ludwigshafen found the lack of IRB approval and this is unethical. It does not mean that the research results per se are fraudulent. The investigating committee is systematically assessing the veracity of the findings presented in Dr. Boldt's articles against patient and laboratory records. We will communicate to our readers any finding of data fabrication or misrepresentation identified by the investigating committee. 